\title{
Optimization and Preliminary Physicochemical Characterization of Pectin Extraction from Watermelon Rind (Citrullus lanatus) with Citric Acid
}

\author{
José Pérez $\mathbb{D}$, Karina Gómez $\mathbb{D}$, and Lorena Vega \\ Department of Chemical Engineering, Bioprocess Research Group, Universidad del Atlántico, Puerto Colombia 081001, Colombia \\ Correspondence should be addressed to José Pérez; jandrespmen@gmail.com
}

Received 26 October 2021; Accepted 14 December 2021; Published 6 January 2022

Academic Editor: Zheng-Fei Yan

Copyright (c) 2022 José Pérez et al. This is an open access article distributed under the Creative Commons Attribution License, which permits unrestricted use, distribution, and reproduction in any medium, provided the original work is properly cited.

\begin{abstract}
Watermelon rind was used for the pectin extraction with citric acid as the extractant solvent. The effects of $\mathrm{pH}(2.0-3.0)$, extraction time (45-75 min), and liquid-solid ratio $(10: 1$ to $40: 1 \mathrm{~mL} / \mathrm{g})$ on the pectin yield, degree of esterification, methoxyl content, and anhydrouronic acid content were investigated using Box-Behnken surface response experimental design. The $\mathrm{pH}$ was the most significant variable for the pectin yield and properties. The responses optimized separately showed different optimal conditions for each one of the variables studied in this work. Therefore, the desirability function was used to determine the sole theoretical optimum for the highest pectin yield and highest anhydrouronic acid content, which was found to be $\mathrm{pH}$ of 2.0, extraction time of $62.31 \mathrm{~min}$, and liquid-solid ratio of $35.07 \mathrm{~mL} / \mathrm{g}$. Under this optimal condition, the pectin yield, degree of esterification, methoxyl content, and anhydrouronic acid content were $24.30 \%, 73.30 \%, 10.45 \%$, and $81.33 \%$, respectively. At optimal conditions, watermelon rind pectin can be classified as high methoxyl and rapid-set pectin with high quality and high purity. Practical Applications. This study evaluated the pectin extraction from watermelon rind and carried out an optimization of multiple responses as a function of $\mathrm{pH}$, time, and liquid-solid ratio to obtain the best preliminary quality parameters (pectin yield and anhydrouronic acid content). The results revealed that watermelon rind waste can be an inexpensive source to obtain good pectin quality and high purity. According to the chemical characterization and physicochemical properties studied, the extracted pectin from watermelon rind would have a high potential to be used in food industry.
\end{abstract}

\section{Introduction}

Watermelon (Citrullus lanatus) is a Cucurbitaceae, creeping herbal plant or climbing plant characterized as a large and juicy fruit. Watermelon fruit is composed of flesh (edible part), seeds distributed throughout the flesh, and the rind representing $30-40 \%$ of the total weight $[1,2]$. Health benefits such as prevention against cardiovascular diseases are attributed to the fruit $[3,4]$. The literature has determined that the watermelon seeds [5] and watermelon rinds [6] contain antioxidant properties. Watermelon is mainly used for local production of juices, which generate large amounts of waste without a proper disposal treatment. These watermelon residues have great potential to produce pectin and other value-added products.
Pectin is a linear polysaccharide mainly composed of anhydrogalacturonic acid units with $\alpha(1 \longrightarrow 4)$ bonds, and the carboxyl acid groups are esterified with methyl groups partially [7]. Its structure includes other components such as neutral sugars: arabinose, galactose, rhamnose, and xylose $[7,8]$, which can react with methanol to form methyl esters or neutralized by a base [9]. Pectin has gelling properties that are used for the aqueous gel formation in the food industry $[10,11]$. Some of the pharmaceutical applications of pectin are to diminish lipid digestion [12], to improve lipid hepatic accumulation [13], glucose tolerance for antidiabetic effects [14], and its anti-inflammatory activity in high methoxyl pectins [15]. Recently, the low hydrophilic of pectin has taken advantage to improve carrier properties and diffusion control of nicotine in transdermal patches [16, 
17] and drug delivery such as theophylline tablets [18] and lidocaine and aspirin in ionic liquid [19].

The variables that affect the extraction yield are $\mathrm{pH}$, temperature, time, and liquid-solid ratio (LSR). The quality parameters of pectin include extraction yield and properties such as ash content [20], free acidity [21], methoxyl content [22], degree of esterification [23], anhydrogalacturonic acid content $[24,25]$, and Fourier transform infrared spectroscopy (FTIR) analysis [26, 27]. Pectin is classified through its degree of esterification (DE) due to define its gelling properties. High methoxyl pectins are characterized by forming gels in high soluble solids and acidic systems, which have galacturonic acid units that are more than 50\% (DE $>50 \%$ ) esterified with methyl groups. In low methoxyl pectins ( $\mathrm{DE}<50 \%$ ), the gelation occurs on a widespread $\mathrm{pH}$ range than high methoxyl pectins and requires the presence of divalent cations $[7,8,28]$.

The primary sources of industrial pectin extraction are apple pomace and citrus peels [28, 29]. However, pectin from agroindustrial process wastes is generating a great interest because their use can reduce environmental impacts provoked by themselves and give added value to the agroindustrial production chain. Many biological residues such as pomelo peels $[30,31]$, banana peels [32], mango peels [33, 34], melon peels [11], durian fruit-hulls [35], and heads of sunflower [25] have been utilized to obtain pectin. Hence, watermelon rind can be used to produce pectin, while adding value to the watermelon's agribusiness.

Several works have reported the extraction of pectin from watermelon wastes by using different methods such as acid hydrolysis $[36,37]$ and assisted microwave extraction $[38,39]$. However, the acid hydrolysis is the most employed method for the pectin extraction from food waste. Therefore, the objectives of this study are to optimize and characterize the pectin extraction from watermelon rind using citric acid as solvent for extraction through the response surface methodology (RSM) and determine optimal conditions for the highest pectin yield and anhydrouronic acid content (AUA) simultaneously.

\section{Materials and Methods}

2.1. Sample Preparation. Watermelon rinds were obtained from a local market of watermelon juices located in the Barranquilla center and around the Universidad del Atlántico, Colombia. They were washed, manually cut, and heated in distilled water until boiling to denature enzymes and inactive microorganisms [40]. The collected material was milled for homogenization and was dried in a convection oven at a temperature no higher than $80^{\circ} \mathrm{C}$ for 24 hours. Finally, the treated watermelon rind was packed and stored in a desiccator for later use.

2.2. Chemicals and Solvents. All chemicals and solvents such as citric acid, ethanol, and methanol used were of analytical grade.

2.3. Pectin Extraction. The pectin extraction was carried out through acid hydrolysis with citric acid, according to the methodology with some modifications [41]. The dried watermelon rind was stirred in citric acid solutions with the following defined conditions for all runs of the BoxBehnken design: $\mathrm{pH}(2.0,2.5$, and 3.0); extraction time (45, 60 , and $75 \mathrm{~min}$ ), and liquid-solid ratio $(10: 1,25: 1$, and $40: 1 \mathrm{~mL} / \mathrm{g}$ ) at a constant temperature of $80^{\circ} \mathrm{C}$. The resultant slurry was vacuum filtered with a microcloth using vacuum pressure. The residual liquid was precipitated with methanol in a $60 \%$ volume solution. The obtained precipitate was washed three times with $70 \%$ ethanol and was subsequently rewashed with $96 \%$ ethanol. The collected precipitate was dried in a convection oven until constant weight at $50^{\circ} \mathrm{C}$ for 12 hours.

2.4. Pectin Yield. The pectin yield of watermelon rind on a dry weight basis was determined as follows [10, 42]:

$$
\text { Pectin yield }=\frac{\text { weight of dried pectin }(\mathrm{g})}{\text { weight of dried watermelon ring }(\mathrm{g})} \times 100 \text {, }
$$

where the dried pectin was obtained after the treatment of filtration, precipitation, and drying; the dried watermelon rind was collected as result of sample preparation.

\subsection{Pectin Characterization}

2.5.1. Determination of Degree of Esterification and Anhydrouronic Acid Content. The degree of esterification and the anhydrouronic acid content were determined by titration relating the methoxyl content with the equivalent weight. $0.50 \mathrm{~g}$ of watermelon rind pectin was dissolved into ethanol/water solution $(1: 20 v / v) ; 5$ drops of phenol red indicator were added, and the sample was titrated with $0.1 \mathrm{~N}$ sodium hydroxide $\left(V_{1}, \mathrm{~mL}\right)$ until the indicator changed. Then, $25 \mathrm{~mL}$ of $0.25 \mathrm{~N} \mathrm{NaOH}$ was added, and the sample was heated and stirred vigorously. Five drops of phenol red and $25 \mathrm{~mL}$ of $0.25 \mathrm{~N} \mathrm{HCl}$ were added again, and it was titrated with $0.1 \mathrm{~N} \mathrm{NaOH}\left(V_{2}, \mathrm{~mL}\right)$ until the color changes from yellow to faint pink endpoint [43]. The $\mathrm{MeO}$ and the DE were then calculated according to Equation (2) $[22,31]$ and Equation (3) $[11,23,44]$, respectively.

$$
\begin{gathered}
\mathrm{MeO}(\%)=\frac{V_{2}(\mathrm{~mL}) 0.1(\mathrm{~N}) 31}{\text { weight of sample }(\mathrm{mg})} \times 100, \\
\operatorname{DE}(\%)=\frac{V_{2}(\mathrm{~mL})}{V_{1}(\mathrm{~mL})+V_{2}(\mathrm{~mL})} \times 100 .
\end{gathered}
$$

Equation (4) was used to calculate the anhydrouronic acid content [22].

$$
\operatorname{AUA}(\%)=\frac{0.1(\mathrm{~N})\left(V_{1}(\mathrm{~mL})+V_{2}(\mathrm{~mL})\right) 176}{\text { weight of sample }(\mathrm{mg})} \times 100,
$$

where 176 is the molecular weight of anhydrouronic acid expressed as mg/meq and $V_{1}$ and $V_{2}$ were the volumes used for first and second titration, respectively. 
2.6. Fourier Transform Infrared Spectroscopy. Fourier transform infrared (FTIR) spectra of the extracted pectin were used to evaluate its structural chemical properties. FTIR analysis was performed in the SHIMADZU (IRAffinity-1) spectrometer with a resolution of $4 \mathrm{~cm}^{-1}$ and 130 scans of wavelengths ranging from 4000 to $400 \mathrm{~cm}^{-1}$.

2.7. Experimental Design. The Box-Behnken design response surface design was used to evaluate the effect of three independent variables such as $\mathrm{pH}\left(X_{1}: 2.0-3.0\right)$, the extraction time $\left(X_{2}: 45-75 \mathrm{~min}\right)$, and the liquid-solid ratio, LSR $\left(X_{3}\right.$ : $10-40 \mathrm{~mL} / \mathrm{g}$ ) on simultaneous responses (pectin yield, the $\mathrm{MeO}$, the DE, and AUA). Table 1 summarizes the levels and code of three independent variables.

The experimental design and variance analysis (ANOVA) were performed using R-programming software 4.0.2. The response variables were fitted to the second-order polynomial model as given for the following Equation (9):

$$
Y=B_{0}+\sum_{i=1}^{3} B_{i} X_{i}+\sum_{i=1}^{3} B_{i i} X_{i}^{2}+\sum_{i=1}^{2} \sum_{j=i+1}^{3} B_{i j} X_{i} X_{j}
$$

where $Y$ is the response variable; $B_{0}, B_{i}, B_{i i}$, and $B_{i j}$ are the coefficient terms for the regression model; and $X_{i}$ and $X_{j}$ are the levels of independent variables. The responses were initially optimized separately to predict the 3D surface and the maximum values. Latterly, an optimization of simultaneous responses using the desirability function [45] was performed.

\section{Results and Discussion}

3.1. Experimental Results and Quality Parameters. Table 2 presents the experimental values obtained for pectin yield, methoxyl content, degree of esterification, and anhydrouronic acid content at each Box-Behnken design (BBD) point. The pectin yield range (4.19-27.86\%) was within the typical values reported of $15-20 \%$ and $30-35 \%$ for dried apple pomace and citric peels, respectively [28]. The results indicate that the watermelon rind pectin can be classified as high methoxyl pectin [29] due to its DE and methoxyl content $(\mathrm{MeO})$ which were higher than the reference values of $50 \%$ and $6.7 \%$ [46], respectively. Furthermore, according to the Food Agriculture Organization (FAO) and the World Health Organization (WHO), the AUA suggests that a high-quality pectin (AUA $>65 \% \mathrm{FAO} / \mathrm{WHO}$ ) was obtained [47], except for runs carried out at $\mathrm{pH} 3.0$.

3.2. Statistical Analysis. The analysis of variance (ANOVA) of the results was used to determine the effects of $\mathrm{pH}\left(X_{1}\right)$, extraction time $\left(X_{2}\right)$, and liquid-solid ratio $\left(X_{3}\right)$ on each of the responses of watermelon rind pectin (Table 3$)$. ANOVA revealed that the linear effect $\left(X_{1}\right)$ was significant $(p<0.05)$ for pectin yield, $\mathrm{MeO}$, and AUA. Interactions $\left(X_{2}: X_{3}\right)$ had significant for $\mathrm{DE}$ and $\mathrm{MeO}$. Furthermore, square effects $X_{1}{ }^{2}$ and $X_{2}{ }^{2}, X_{1}{ }^{2}$ and $X_{3}{ }^{2}$, and $X_{2}{ }^{2}$ were also significant for $\mathrm{MeO}, \mathrm{AUA}$, and DE, respectively.

By using multiple regression analysis on the experimental responses, the second-order model was utilized to fit
TABLE 1: Levels and code of variables chosen for the Box-Behnken design.

\begin{tabular}{lccc}
\hline \multirow{2}{*}{ Dependent variables } & \multicolumn{3}{c}{ Real values of coded levels } \\
& -1 & 0 & 1 \\
\hline$X_{1}: \mathrm{pH}$ & 2.0 & 2.5 & 3.0 \\
$X_{2}:$ time (min) & 45 & 60 & 75 \\
$X_{3}:$ liquid-solid ratio, LSR $(\mathrm{mL} / \mathrm{g})$ & $10: 1$ & $25: 1$ & $40: 1$ \\
\hline
\end{tabular}

experimental data and predict the effects of dependent variables. The validity of the model could be confirmed because the lack-of-fit tests were not significant, and the following determination coefficients $\left(R^{2}\right) 0.9162,0.8841,0.9338$, and 0.9301 were obtained for pectin yield, DE, MeO, and AUA, respectively. These results show that the calculated responses by the model were reliable and adequate. The second-order equations (coded factors) for pectin yield (Equation (6)), DE (Equation (7)), MeO (Equation (8)), and AUA (Equation (9)) were given as follows

$$
\begin{aligned}
\operatorname{Pectin} y \text { yeld }(\%)= & 11.99-7.32 X_{1}+0.65 X_{2}+1.17 X_{3} \\
& -0.89 X_{1} X_{2}-2.69 X_{1} X_{3}-0.92 X_{2} X_{3} \\
& +3.41 X_{1}^{2}-3.03 X_{2}^{2}-2.42 X_{3}^{2},
\end{aligned}
$$

$$
\begin{aligned}
\operatorname{DE}(\%)= & 73.67-0.17 X_{1}+0.025 X_{2}+1.47 X_{3}+0.82 X_{1} X_{2} \\
& +0.50 X_{1} X_{3}+3.99 X_{2} X_{3}-2.48 X_{1}^{2}-3.10 X_{2}^{2}+1.74 X_{3}^{2},
\end{aligned}
$$

$$
\begin{gathered}
\mathrm{MeO}(\%)=10.33-1.26 X_{1}-0.16 X_{2}+0.28 X_{3} \\
+0.21 X_{1} X_{2}-0.22 X_{1} X_{3}+0.99 X_{2} X_{3} \\
-1.24 X_{1}^{2}-0.97 X_{2}^{2}-0.57 X_{3}^{2}, \\
\operatorname{AUA}(\%)=79.59-9.87 X_{1}-1.40 X_{2}+0.80 X_{3}+0.78 X_{1} X_{2} \\
-1.93 X_{1} X_{3}+3.96 X_{2} X_{3}-7.24 X_{1}^{2}-4.81 X_{2}^{2}-5.97 X_{3}^{2} .
\end{gathered}
$$

3.3. Effect of Independent Variables on Pectin Yield. ANOVA showed that $\mathrm{pH}$ (linear effect) was the only variable that affected pectin yield significantly [48]. The determination coefficient indicates that $91.62 \%$ of the total variation can be explained by the quadratic model (Equation (6)), which suggests that the model is suitable to predict the yield pectin from watermelon rind under the experimental conditions evaluated in this work. Figure 1(a) shows that the pectin yield was favored at lower $\mathrm{pH}$ (negative regression term), and the higher pectin yield was obtained at the lowest $\mathrm{pH}$ of 2.0. The carboxyl groups present in pectin are hydrated due to the acidified extraction solvent at lower $\mathrm{pH}$; the loss of charges in carboxyl groups tends to reduce the repulsive forces, promoting the pectin precipitation [10]. Indeed, more pectin dissolution by hydrolysis of nonsoluble pectin and increasing of pectin mass transfer from the plant source at lowering $\mathrm{pH}$ are shown by the 
TABLE 2: Experimental conditions of pectin extraction with citric acid and responses for the Box-Behnken experimental design.

\begin{tabular}{|c|c|c|c|c|c|c|c|}
\hline \multirow{2}{*}{ Run } & \multicolumn{3}{|c|}{ Independent variables } & \multicolumn{4}{|c|}{ Experimental responses } \\
\hline & $X_{1}^{\mathrm{a}}$ & $X_{2}^{\mathrm{b}}(\min )$ & $X_{3}{ }^{\mathrm{c}}(\mathrm{g} / \mathrm{mL})$ & Yield (\%) & $\mathrm{DE}(\%)$ & $\mathrm{MeO}(\%)$ & AUA (\%) \\
\hline 1 & 2.0 & 45 & 25 & 17.02 & 71.13 & 9.91 & 79.11 \\
\hline 2 & 3.0 & 45 & 25 & 5.31 & 67.71 & 7.45 & 62.49 \\
\hline 3 & 2.0 & 75 & 25 & 21.23 & 66.83 & 8.36 & 71.02 \\
\hline 4 & 3.0 & 75 & 25 & 5.95 & 66.67 & 6.75 & 57.52 \\
\hline 5 & 2.0 & 60 & 10 & 14.59 & 71.42 & 9.39 & 74.68 \\
\hline 6 & 3.0 & 60 & 10 & 4.19 & 71.53 & 6.82 & 54.11 \\
\hline 7 & 2.0 & 60 & 40 & 27.16 & 73.33 & 10.66 & 82.50 \\
\hline 8 & 3.0 & 60 & 40 & 5.99 & 75.44 & 7.21 & 54.23 \\
\hline 9 & 2.5 & 45 & 10 & 6.77 & 73.43 & 9.40 & 72.69 \\
\hline 10 & 2.5 & 75 & 10 & 8.80 & 68.22 & 7.89 & 65.69 \\
\hline 11 & 2.5 & 45 & 40 & 6.12 & 68.42 & 7.71 & 64.00 \\
\hline 12 & 2.5 & 75 & 40 & 4.47 & 79.17 & 10.16 & 72.83 \\
\hline 13 & 2.5 & 60 & 25 & 11.48 & 73.47 & 10.51 & 81.24 \\
\hline 14 & 2.5 & 60 & 25 & 11.50 & 74.61 & 10.44 & 79.46 \\
\hline 15 & 2.5 & 60 & 25 & 13.00 & 72.93 & 10.03 & 78.08 \\
\hline
\end{tabular}

${ }^{\mathrm{a}} X_{1}$ (pH with three levels: 2.0, 2.5, and 3.0), ${ }^{\mathrm{b}} X_{2}$ (extraction time with three levels: 45,60 , and 75 minutes), and ${ }^{\mathrm{c}} X_{3}$ (LSR with three levels: 10,25 , and $40 \mathrm{~mL} / \mathrm{g}$ ).

TAble 3: Results of ANOVA for pectin yield, DE, MeO, and AUA.

(a)

\begin{tabular}{|c|c|c|c|c|c|c|c|c|c|c|}
\hline \multirow{2}{*}{ Source } & \multicolumn{5}{|c|}{ Pectin yield (\%) } & \multicolumn{5}{|c|}{ DE (\%) } \\
\hline & Df & Sum sq & Mean sq & $F$ value & $\operatorname{Pr}(>F)$ & Df & Sum sq & Mean sq & $F$ value & $\operatorname{Pr}(>F)$ \\
\hline Model & 9 & 584.37 & 64.93 & 6.08 & $0.0306^{*}$ & 9 & 156.22 & 17.36 & 4.24 & 0.0631 \\
\hline Linear & 3 & 443.10 & 147.70 & 13.82 & $0.0074^{* *}$ & 3 & 17.52 & 5.84 & 1.43 & 0.3911 \\
\hline Interaction & 3 & 35.57 & 11.86 & 1.11 & 0.4274 & 3 & 67.34 & 22.45 & 5.48 & $0.0488^{*}$ \\
\hline Square & 3 & 105.70 & 35.23 & 3.30 & 0.1159 & 3 & 71.36 & 23.79 & 5.81 & $0.0438^{*}$ \\
\hline Residuals & 5 & 53.44 & 10.69 & & & 5 & 20.48 & 4.10 & & \\
\hline Lack of fit & 3 & 51.92 & 17.31 & 22.77 & 0.0424 & 3 & 19.00 & 6.33 & 8.61 & 0.1058 \\
\hline Pure error & 2 & 1.52 & 0.76 & & & 2 & 1.47 & 0.74 & & \\
\hline Total & 28 & 1275.62 & & & & 28 & 353.39 & & & \\
\hline
\end{tabular}

(b)

\begin{tabular}{|c|c|c|c|c|c|c|c|c|c|c|}
\hline & \multicolumn{5}{|c|}{$\mathrm{MeO}(\%)$} & \multicolumn{5}{|c|}{ AUA (\%) } \\
\hline & Df & Sum sq & Mean sq & $F$ value & $\operatorname{Pr}(>F)$ & Df & Sum sq & Mean sq & $F$ value & $\operatorname{Pr}(>F)$ \\
\hline Model & 9 & 27.00 & 3.00 & 7.40 & $0.0201^{*}$ & 9 & 1238.65 & 137.63 & 7.84 & $0.0177^{*}$ \\
\hline Linear & 3 & 13.57 & 4.52 & 11.15 & $0.0118^{*}$ & 3 & 800.20 & 266.73 & 15.19 & $0.0060^{* *}$ \\
\hline Interaction & 3 & 4.29 & 1.43 & 3.53 & 0.1041 & 3 & 79.90 & 26.63 & 1.52 & 0.3184 \\
\hline Square & 3 & 9.14 & 3.05 & 7.51 & $0.0267^{*}$ & 3 & 358.55 & 119.52 & 6.81 & $0.0323^{*}$ \\
\hline Residuals & 5 & 2.03 & 0.41 & & & 5 & 87.80 & 17.56 & & \\
\hline Lack of fit & 3 & 1.89 & 0.63 & 9.39 & 0.0978 & 3 & 82.78 & 27.59 & 10.99 & 0.0845 \\
\hline Pure error & 2 & 0.13 & 0.07 & & & 2 & 5.02 & 2.51 & & \\
\hline Total & 28 & 58.06 & & & & 28 & 2652.90 & & & \\
\hline
\end{tabular}

Significant codes: 0 “***”; 0.01 “**”; 0.05 “*”.

literature $[23,24,30,48,49]$. These conditions were shown to have led to increase the pectin release and recovery.
These results were similar to other reported pectins, which showed a significant rise of pectin yield at lower $\mathrm{pH}$ for extracted pectin from mango peels [33] and watermelon 

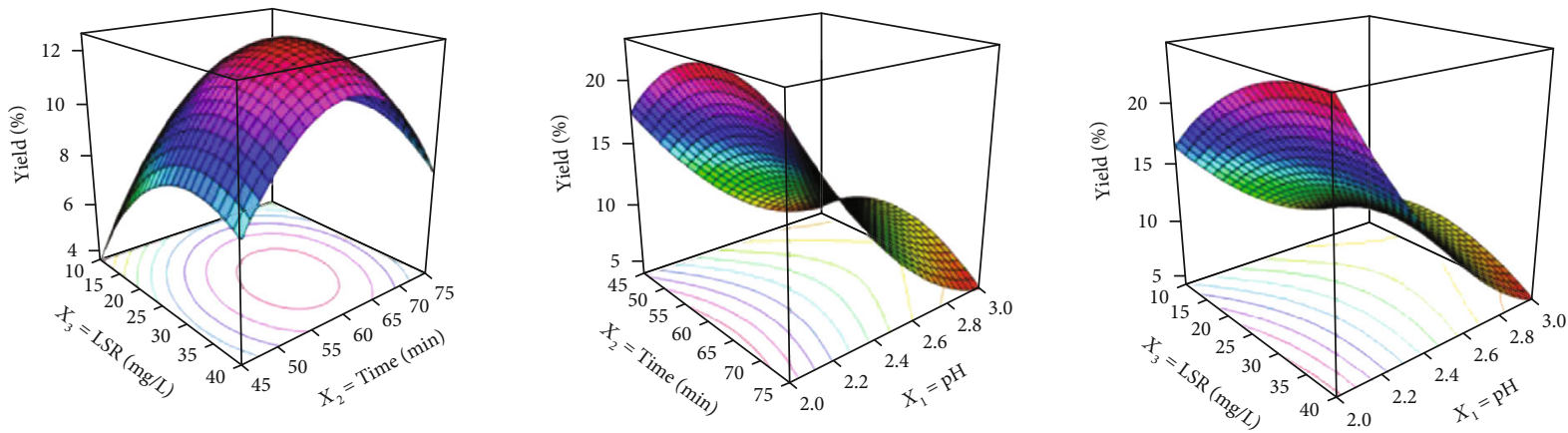

(a) Yield
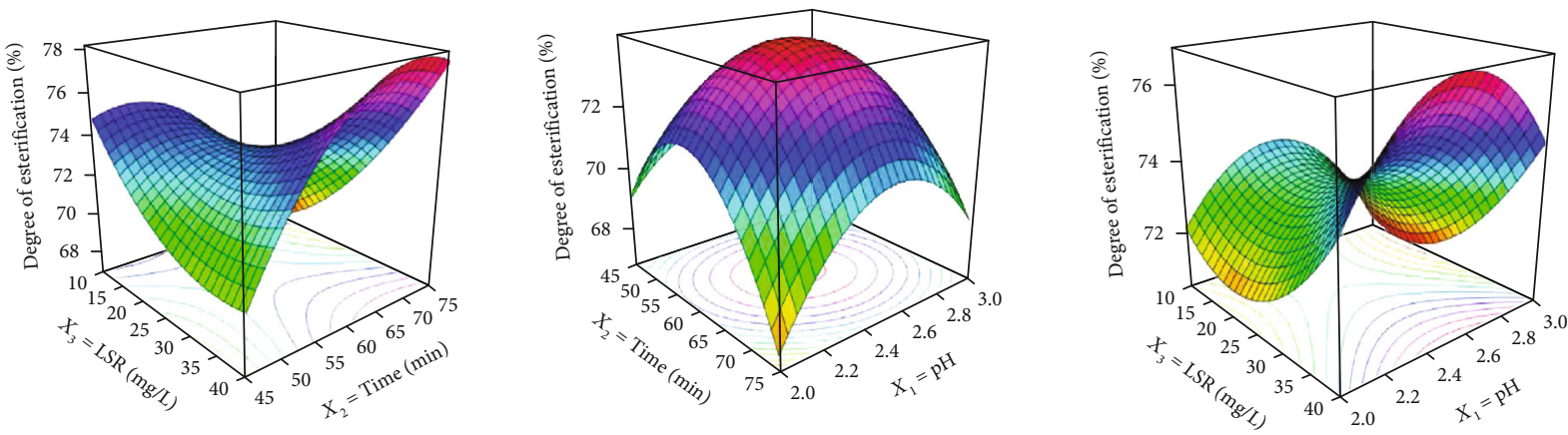

(b) $\mathrm{DE}$
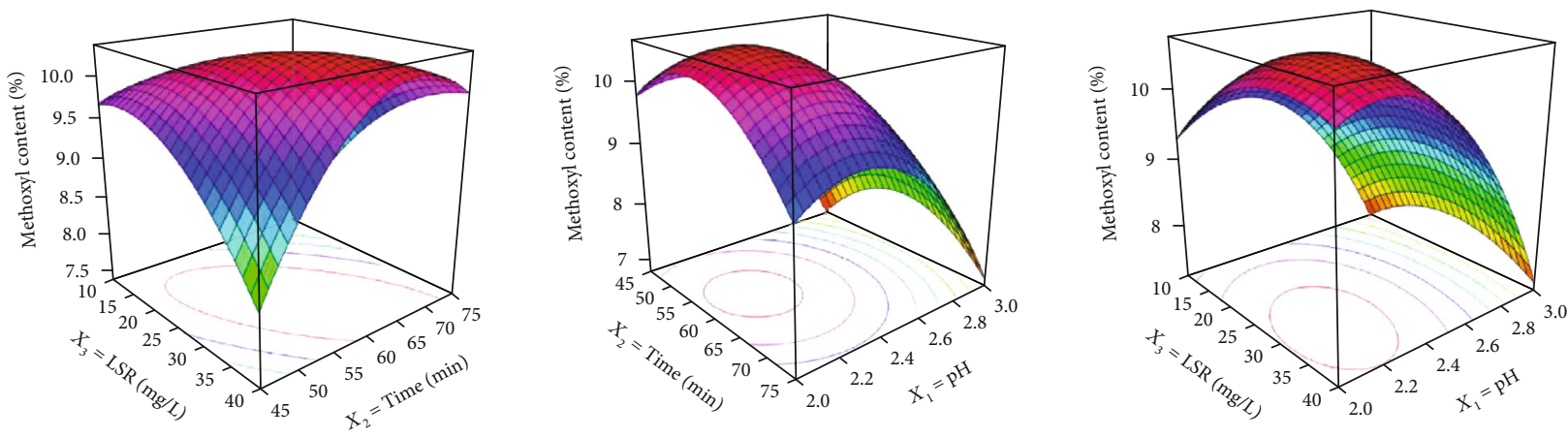

(c) $\mathrm{MeO}$
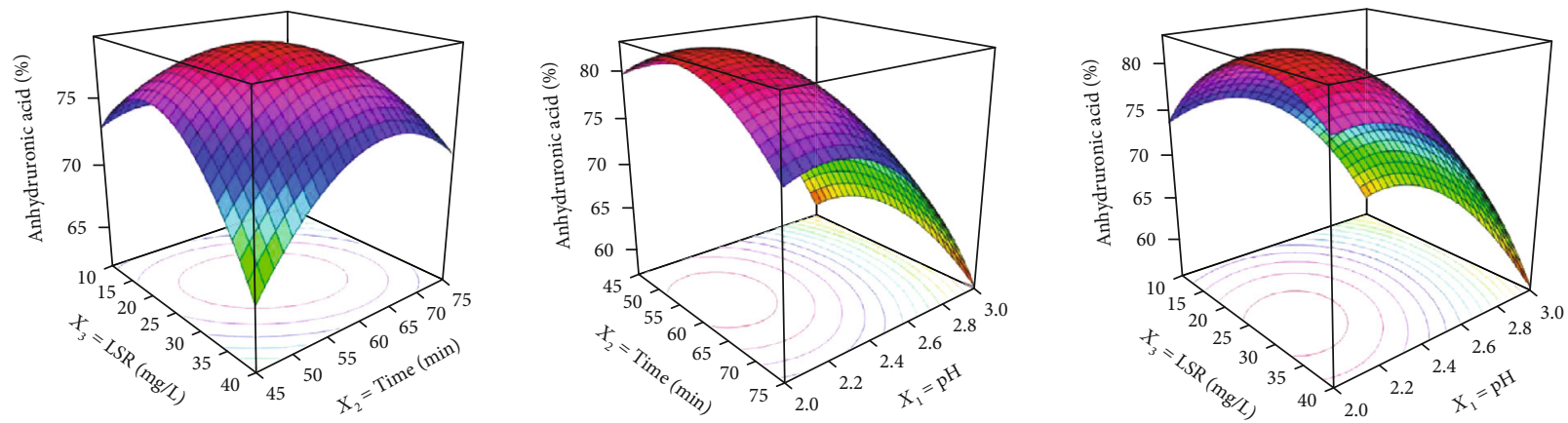

(d) AUA

FIGURE 1: Response surface showing the effect of dependent variables ( $\mathrm{pH}$, time extraction, and LSR) on the pectin yield (a), DE (b), MeO (c), and AUA (d).

rind [38]. Figure 1(a) illustrates that at high points of extraction time $\left(X_{2}\right)$ and low values of LSR $\left(X_{3}\right)$, the pectin yield decreased; this behavior is in agreement with results reported in the pectin extraction from seed watermelon peel
[50] and pectin extraction from carrot pomace [23]. This is likely because of extended extraction time; the citric acid causes the breakdown of glycoside bonds and ester bonds of pectin [51]. On the other hand, excessive or insufficient 
TABLE 4: Optimized responses and theoretical optimum.

\begin{tabular}{lccccc}
\hline Dependent variable & $X_{1}$ & $X_{2}(\mathrm{~min})$ & $X_{3}(\mathrm{~mL} / \mathrm{g})$ & Optimal value $^{\dagger}$ & Theoretical predicted $^{\ddagger}$ \\
\hline Pectin yield (\%) & 2.00 & 62.07 & 36.57 & 24.32 & 24.30 \\
DE (\%) & 2.59 & 70.05 & 40.00 & 78.26 & 73.00 \\
MeO (\%) & 2.23 & 60.97 & 31.12 & 10.72 & 10.45 \\
AUA (\%) & 2.15 & 57.77 & 26.97 & 83.24 & 81.33 \\
\hline
\end{tabular}

${ }^{\dagger}$ Optimum calculated by each model separately. ${ }^{\ddagger}$ Responses at $\mathrm{pH}=2.0$, extraction time $=62.31 \mathrm{~min}$, and $\mathrm{LSR}=35.07 \mathrm{~g} / \mathrm{mL}$.

TABLE 5: Chemical properties of pectin obtained from watermelon rind compared with standard pectin.

\begin{tabular}{lcc}
\hline Properties & Standard pectin & Extracted pectin \\
\hline Ash (\%) & $3.77 \pm 3.39$ & 1.24 \\
Alkalinity of ash (calcium carbonate,\%) & $2.34 \pm 2.90$ & 0.39 \\
Free acid (meq/g) & $0.78 \pm 0.46$ & 1.25 \\
MeO (\%) & $\geq 6.70$ (USP) & 10.66 \\
DE (\%) & $\geq 50$ high methoxyl pectin & 73.33 \\
AUA (\%) & $71-74$ rapid set & $\geq 74$ (USP) \\
\hline
\end{tabular}

amounts of LSR influenced the pectin mass transfer due to the solution saturation or low dissolution capacity. Therefore, the pectin yields were smaller at extreme LSR conditions [50].

3.4. Effect of Independent Variables on DE. As can be seen, in Table 2 and Figure 1(b), the extracted pectin is considered like a high methoxyl pectin with DE ranging from $66.67 \%$ to $75.44 \%$. According to ANOVA, linear effects were not significant, and the interaction between time extraction and LSR $\left(X_{2}: X_{3}\right)$ and the quadratic effect of the time extraction $\left(X_{2}^{2}\right)$ affected the DE (Table 3(a)). High methoxyl pectin (DE $>50 \%$ ) has been obtained from pomelo peel [30], pomelo albedo [21], and watermelon rind [36], indicating that our findings are in agreement with these previous works. It was noticed that the DE increased for more extensive extraction time. These results are in accordance with the reported values given in pectin from cocoa husks [20]. Under the conditions tested in this study, the DE showed that the obtained watermelon rind pectin was characterized with a low degree of deesterification of polygalacturonic chains.

3.5. Effect of Independent Variables on $\mathrm{MeO}$. The methoxyl content listed in Table 2 varied from 6.75 to $10.66 \%$. Based on the regression analysis (Equation (8)), it can be suggested that $\mathrm{pH}$ (linear and quadratic coefficients) negatively influenced the $\mathrm{MeO}$ (Figure 1(c)). In other words, decreasing $\mathrm{pH}$ led to get higher the methoxyl content. Other significant factors were interaction coefficient terms $\left(X_{2}: X_{3}\right.$, Figure $1(\mathrm{c})$ ) and quadratic coefficient of the time extraction $\left(X_{2}{ }^{2}\right)$. In addition, the $R$ squared pointed out that $6.62 \%$ of data variability could not be explained by Equation (8). The acidic extraction (citric acid) was favorable towards the methoxylation of side acid groups of polygalacturonic chains. This is probably due to the methoxylation which was catalyzed by acidity medium (low $\mathrm{pH}$ ), which increases the reactivity of the acid groups by shifting the equilibrium forward to methyl ester formation. The methoxyl content of citrus peel pectin and apple pectin [52] was comparable with obtained results.

3.6. Effect of Independent Variables on AUA. Similar to the pectin yield, $\mathrm{pH}$ was the most significant variable for the anhydrouronic acid content. Unlike the yield, the quadratic coefficient term of LSR $\left(X_{3}^{2}\right)$ was also significant. In Figure $1(\mathrm{~d})$, it was observed that AUA (purity pectin) increased at lower levels of $\mathrm{pH}$ and low-intermediate levels of LSR. However, the highest value of AUA (82.50\%) was obtained at the lowest $\mathrm{pH}(2.0)$, greatest LSR $(40 \mathrm{~mL} / \mathrm{g})$, and time extraction of 60 minutes. Several works from different plant sources like orange peels [49], ponkan peels [24], and banana peels [32] have shown that low $\mathrm{pH}$ and LSR between 20 and $25 \mathrm{~mL} / \mathrm{g}$ increased the AUA [20, 24, 49]. By contrast, it has been previously shown that longer extraction time improved pectin purity $[20,25,32]$, which did not agree with the results in the present study.

3.7. Pectin Optimization. Based on the polynomial models fitted for each of the responses, a separate optimization process was carried out to find out the optimal conditions that maximized pectin yield, $\mathrm{DE}, \mathrm{MeO}$, and AUA independently. Different optimal conditions were obtained (Table 4 and Figure 1). These optimal predictions confirmed the strong influence of $\mathrm{pH}$ (low values) on the pectin yield, $\mathrm{MeO}$ content, and AUA content as well as previously shown. It is noteworthy that for all responses except DE, the optimal conditions were at low $\mathrm{pH}$, intermediate values of time extraction (nearly $60 \mathrm{~min}$ ), and midpoints to high levels of LSR for the study regions tested in this work.

In order to unify to one optimal condition (theoretical optimum), an analysis of the multiple responses through the desirability discontinuous functions [45] using R- 


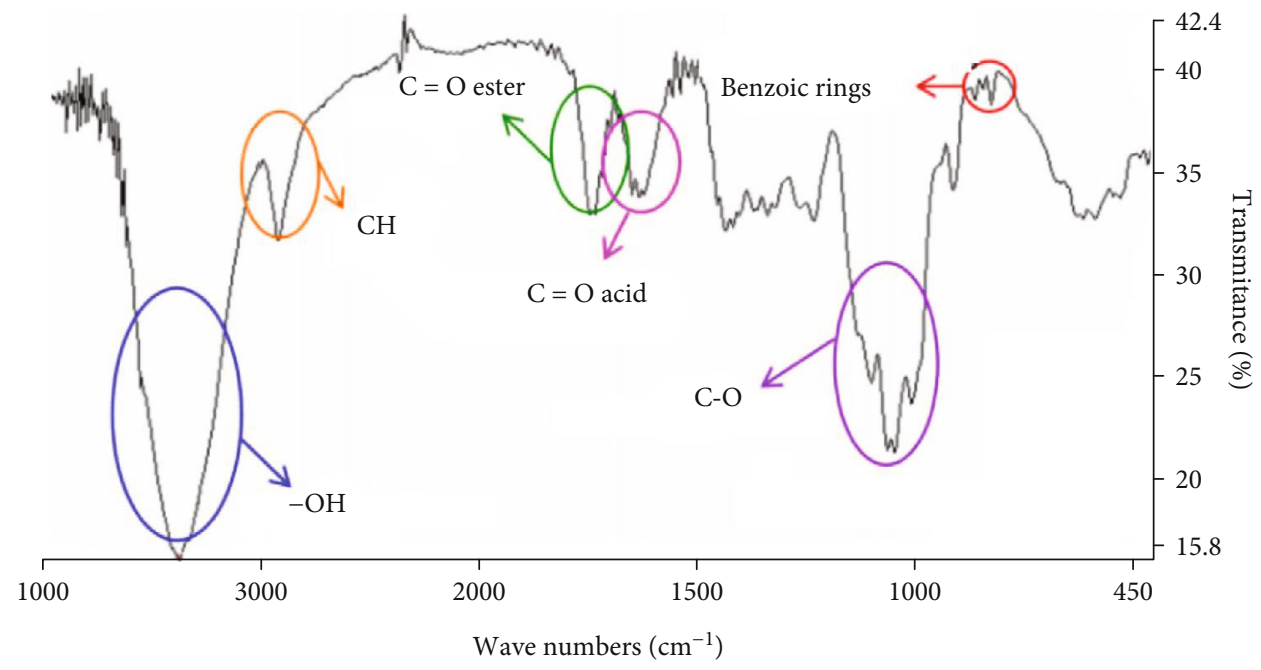

(a)

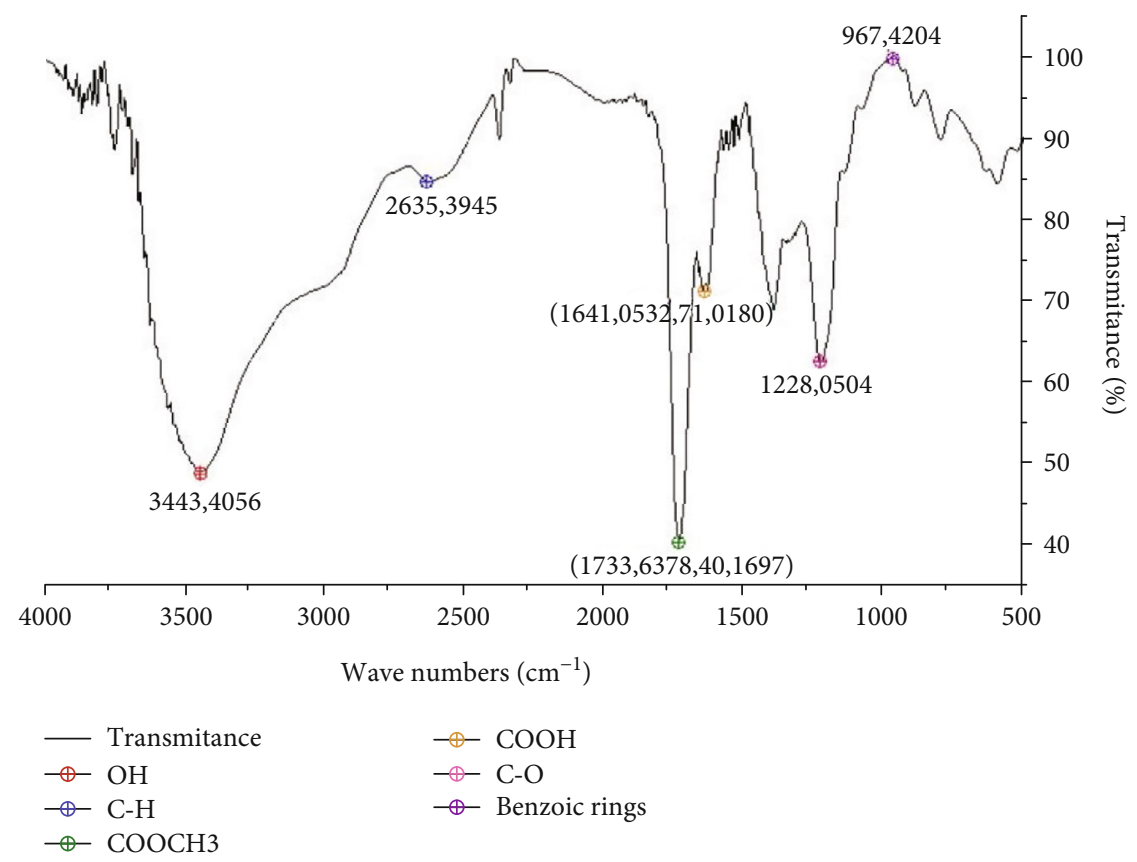

(b)

FIGURE 2: FTIR spectra of pectin: (a) commercial rapid-set pectin and (b) extracted pectin from watermelon rind.

programming software [53] was performed. The conditions obtained for the highest pectin yield and highest AUA simultaneously were found at $\mathrm{pH}$ of 2.0 , extraction time of $62.31 \mathrm{~min}$ and LSR of $35.07 \mathrm{~g} / \mathrm{mL}$ (Table 4). Theoretical optimum was quite similar to the optimal conditions predicted for pectin yield model in Equation (6) as is shown in Table 4. In fact, the theoretical optimum pectin yield $(24.30 \%)$ can be considered equivalent to highest predicted by Equation (6), which is slightly lower than the experimental value, $27.16 \%$. In addition, regarding the other responses, the theoretical predictions are very good, similar to the experimental values (Table 2). According to these findings, the models were well fitted to predict the effect of independent variables and their responses.
The optimal pectin yield (24.30\%) was comparable with other studies that also used the desirability function to optimize simultaneous responses. The pectin extraction from melon peels [11], mango peels [34], and ponkan peels [24] reported maximum pectin yields of $29.48 \%, 30.0 \%$, and $25.6 \%$, respectively. Previous works from watermelon rind have reported pectin yields of approximately 19\% [38] and $25 \%[37,39]$. It has shown that citric acid was a better solvent extractant than hydrochloric acid in the pectin extraction from watermelon rind [36]. Nevertheless, their maximum pectin yield (8.38\%) [36] obtained was very low compared to the reported values by this study and previous works, despite their optimal conditions ( $\mathrm{pH}$ of 2.0, extraction time of $180 \mathrm{~min}$, LSR of 25 , and temperature of $80^{\circ} \mathrm{C}$ ) 
[36], which were pretty similar to ours. This might be due to the Colombian variety of watermelon and using methanol as a precipitating agent, which has shown to be a better precipitating agent than ethanol in the extraction of pectin from pomelo albedo [21]. For this reason, the highest properties of pectin were obtained from watermelon rind.

3.8. Characterization of Pectin. The characteristics of extracted pectin from watermelon rind using citric acid under the highest yield experimental conditions $(\mathrm{pH}$ of 2.0, time of $60 \mathrm{~min}$, and LSR of $40 \mathrm{~mL} / \mathrm{g}$ ) were comparable with commercial pectin (Merck). Table 5 shows the remarkable properties of the pectin obtained. The ash content and alkalinity of ash were $1.24 \%$ and $0.39 \%$, respectively, which were lower than the accepted levels for the standard pectin. The ash content is a measure of the degree of purity [52] and quality [42] of pectin. Based on these results, the extracted pectin presented low amounts of soluble solids and high purity. Free acid registered a high value compared to standard pectin; this might be due to the chemical nature of carboxyl groups, which in harsh $\mathrm{pH}$ conditions are hydrolyzed, increasing pectin acidity.

High methoxyl and rapid-set pectin was obtained from watermelon rind because of the $\mathrm{MeO}(10.66 \%)$, and $\mathrm{DE}$ (73.33\%) values are ranged for this pectin type (Table 5). Rapid-set pectin is used in high-sugar jams, jellies, and marmalades $[7,8]$, indicating that pectin from watermelon rind could likely be employed in food applications. High methoxyl pectin from watermelon rind has been previously reported [36-39], and these findings are in agreement with obtained results. From the results of AUA, the extracted pectin had a value of $82.5 \%$, which was higher than those reported by similar works with watermelon rind [36-38] and as well as the percent requirements for commercial food or pharmaceutical purpose [46, 47]. It should be pointed out that the AUA is a determining quality parameter and gelling properties of pectin $[23,46]$. Therefore, the results related to AUA also indicated that high-quality pectin was extracted from watermelon rind by using citric acid.

3.9. FTIR Analysis. According to the properties shown for the extracted pectin in this work (Table 4), the FTIR spectra were compared to commercial rapid-set pectin [54] as is illustrated in Figure 2. FTIR analysis at highest yield experimental conditions ( $\mathrm{pH}$ of 2.0, time extraction of $60 \mathrm{~min}$, and LSR of $40 \mathrm{~mL} / \mathrm{g}$ ) identified the main functional groups present in this type of pectin. The peaks related to $\mathrm{O}-\mathrm{H}$ and $\mathrm{C}-\mathrm{H}$ stretching vibrations were between $3500-3250 \mathrm{~cm}^{-1}$ and $3000-2700 \mathrm{~cm}^{-1}$, respectively. Stretching vibrations (=CO) of esterified carboxyl groups and free carboxyl groups $\left(1800-1600 \mathrm{~cm}^{-1}\right)$ were observed in the fingerprint regions of the pectin spectrum [10,55-57]. The peak of $\mathrm{CH}$ bending vibrations for pyranose ring (approximately $1338 \mathrm{~cm}^{-1}$ ) and the peak of $\mathrm{COO}^{-}$stretching vibration for ester groups $\left(1330-1210 \mathrm{~cm}^{-1}\right)$ can be assigned in Figure 2 [55]. Furthermore, the characteristic overlapped peaks of glycoside bonds and pyranose cycles around $1000 \mathrm{~cm}^{-1}$ and weak peaks (830$500 \mathrm{~cm}^{-1}$ ) associated with $\alpha$ - and $\beta$-configurations were identified, indicating that the pectin is the principal compo- nent $[55,58]$. The bands of FTIR spectra of the obtained pectin were similar to reported with analogous work of pectin extraction from watermelon rind [36].

\section{Conclusions}

In this study, the pectin extracted from watermelon rind with citric acid is considered a high methoxyl pectin (DE $>50 \%$ and $\mathrm{MeO}>6.7 \%)$ and has high quality (AUA $>65 \%, \mathrm{FAO} / \mathrm{WHO}$, except for runs at $\mathrm{pH}$ of 3.0). Based on the results of $\mathrm{BBD}, \mathrm{pH}$ was the most significant variable on the pectin yield and its properties. The simultaneous optimization to obtain the highest pectin yield and highest AUA showed that the optimal conditions were found at $\mathrm{pH}$ of 2.0 (lowest level), extraction time of $62.31 \mathrm{~min}$ (intermediate points), and $35.07 \mathrm{~mL} / \mathrm{g}$ (high- midpoints), which were close to optimal experimental conditions ( $\mathrm{pH}$ of 2.0, time of $60 \mathrm{~min}$, and LSR of $40 \mathrm{~mL} / \mathrm{g}$ ) for the highest yield pectin. Under this optimum pectin yield, $\mathrm{DE}, \mathrm{MeO}$, and AUA were $24.32 \%, 73.33 \%$ (rapid-set pectin), 10.66 , and $82.50 \%$ (AUA $>74 \%$ USP, high quality), respectively. In addition, ash content and alkalinity of ash revealed high purity of pectin at the optimal condition.

\section{Data Availability}

The experimental results of pectin extraction obtained from BBD design, R-Program for ANOVA analysis, and IR-figure of pectin data used to support the findings of this study have been deposited in the Watermelon Pectin Mendeley repository (Perez, Jose [59], "Watermelon Pectin", Mendeley Data, V2, doi:10.17632/fhnyv7zspj.2). Correspondence and requests for materials should be addressed to Jose Perez.

\section{Disclosure}

This document was uploaded to Research Square Preprints for consultation prior to publication; in addition, there are not any suggestions, comments, or recommendations to date [59].

\section{Conflicts of Interest}

The authors declare no competing interests.

\section{Authors' Contributions}

Jose Perez designed and supervised the work and wrote and edited the manuscript. Karina Gomez and Lorena Vega carried out the experiments and chemical analysis. Karina Gomez edited the main manuscript. All authors did the statistical and data analysis.

\section{References}

[1] R. Durán, M. E. Villegas, and I. Nieves, "Caracterización y extracción de citrulina de la corteza de la sandía (Citrullus lanatus "thunb") consumida en Valledupar," Temas Agrarios, vol. 22 , no. 1, pp. 60-67, 2017. 
[2] X. Rico, B. Gullón, J. L. Alonso, and R. Yáñez, "Recovery of high value-added compounds from pineapple, melon, watermelon and pumpkin processing by-products: an overview," Food Research International, vol. 132, 2020.

[3] J. Costa-Rodrigues, O. Pinho, and P. R. R. Monteiro, "Can lycopene be considered an effective protection against cardiovascular disease?," Food Chemistry, vol. 245, pp. 1148-1153, 2018.

[4] R. A. Shanely, J. J. Zwetsloot, T. J. Jurrissen et al., "Daily watermelon consumption decreases plasma sVCAM-1 levels in overweight and obese postmenopausal women," Nutrition Research, vol. 76, pp. 9-19, 2020.

[5] C. Wen, J. Zhang, Y. Feng, Y. Duan, H. Ma, and H. Zhang, "Purification and identification of novel antioxidant peptides from watermelon seed protein hydrolysates and their cytoprotective effects on $\mathrm{H}_{2} \mathrm{O}_{2}$-induced oxidative stress," Food Chemistry, vol. 327, p. 127059, 2020.

[6] H. M. A. Al-Sayed and A. R. Ahmed, "Utilization of watermelon rinds and sharlyn melon peels as a natural source of dietary fiber and antioxidants in cake," Annals of Agricultural Sciences, vol. 58, no. 1, pp. 83-95, 2013.

[7] S. M. Brejnholt, "Pectin," in Food Stabilisers, Thickeners and Gelling Agents, pp. 237-265, Wiley, 2009.

[8] H.-U. Endreß and S. H. Christensen, "Pectins," in Handbook of Hydrocolloids, Elsevier, 2009.

[9] V. Y. Zegada, "Pectin extraction from orange peels waste by microwave assisted acid," Centro de Investigaciones de Procesos Industriales (CIPI), vol. 1, no. 15, pp. 65-76, 2015, http://www .scielo.org.bo/scielo.php?script $=$ sci_arttext $\&$ pid $=S 2518$ 44312015000100007.

[10] C. Muthukumaran, L. Banupriya, S. Harinee et al., "Pectin from muskmelon (Cucumis melo var. reticulatus) peels: extraction optimization and physicochemical properties," Biotech, vol. 7, no. 1, p. 66, 2017.

[11] Z. Raji, F. Khodaiyan, K. Rezaei, H. Kiani, and S. S. Hosseini, "Extraction optimization and physicochemical properties of pectin from melon peel," International Journal of Biological Macromolecules, vol. 98, pp. 709-716, 2017.

[12] M. Espinal-Ruiz, L. P. Restrepo-Sánchez, C. E. NarváezCuenca, and D. J. McClements, "Impact of pectin properties on lipid digestion under simulated gastrointestinal conditions: comparison of citrus and banana passion fruit (Passiflora tripartita var. mollissima) pectins," Food Hydrocolloids, vol. 52, pp. 329-342, 2016.

[13] R. G. Zhu, Y. SunDi, T. P. Li et al., "Comparative effects of hawthorn (Crataegus pinnatifida Bunge) pectin and pectin hydrolyzates on the cholesterol homeostasis of hamsters fed high- cholesterol diets," Chemico-Biological Interactions, vol. 238, pp. 42-47, 2015.

[14] Y. Liu, M. Dong, Z. Yang, and S. Pan, "Anti-diabetic effect of citrus pectin in diabetic rats and potential mechanism via PI3K/Akt signaling pathway," International Journal of Biological Macromolecules, vol. 89, pp. 484-488, 2016.

[15] M. Tummalapalli, M. Berthet, B. Verrier, B. L. Deopura, M. S. Alam, and B. Gupta, "Drug loaded composite oxidized pectin and gelatin networks for accelerated wound healing," International Journal of Pharmaceutics, vol. 505, no. 1-2, pp. 234-245, 2016.

[16] J. Suksaeree, P. Karnsopa, N. Wannaphruek et al., "Use of isolated pectin from a Cissampelos pareira-based polymer blend matrix for the transdermal delivery of nicotine," Journal of
Polymers And The Environment, vol. 26, no. 9, pp. 3531$3539,2018$.

[17] J. Suksaeree, J. Prasomkij, K. Panrat, and W. Pichayakorn, "Comparison of pectin layers for nicotine transdermal patch preparation," Advanced Pharmaceutical Bulletin, vol. 8, no. 3, pp. 401-410, 2018

[18] M. Khoder, V. Schropp, S. Zeitler et al., "A novel natural GRAS-grade enteric coating for pharmaceutical and nutraceutical products," International Journal of Pharmaceutics, vol. 584, article 119392, 2020.

[19] J. Suksaeree, P. Maneewattanapinyo, K. Panrat, W. Pichayakorn, and C. Monton, "Solvent-cast polymeric films from pectin and Eudragit ${ }^{\circledR}$ NE 30D for transdermal drug delivery systems," Journal of Polymers and the Environment, vol. 29, no. 10, pp. 3174-3184, 2021.

[20] S. Y. Chan and W. S. Choo, "Effect of extraction conditions on the yield and chemical properties of pectin from cocoa husks," Food Chemistry, vol. 141, no. 4, pp. 3752-3758, 2013.

[21] S. de la Hoz, B. Vazquez, J. Perez, A. Albis, and L. Quiñones, "Effect of precipitating solvents on the extraction of pectin from the pomelo albedo by acid hydrolysis. Contemporary," Engineering Sciences, vol. 11, no. 78, pp. 3849-3855, 2018.

[22] N. S. M. Ismail, N. Ramli, N. M. Hani, and Z. Meon, "Extraction and characterization of pectin from dragon fruit (Hylocereus polyrhizus) using various extraction conditions," Sains Malaysiana, vol. 41, no. 1, pp. 41-45, 2012.

[23] F. Jafari, F. Khodaiyan, H. Kiani, and S. S. Hosseini, "Pectin from carrot pomace: optimization of extraction and physicochemical properties," Carbohydrate Polymers, vol. 157, pp. 1315-1322, 2017.

[24] C. Colodel, L. C. Vriesmann, R. F. Teófilo, and C. L. de Oliveira Petkowicz, "Extraction of pectin from ponkan (Citrus reticulata Blanco cv. Ponkan) peel: optimization and structural characterization," International Journal of Biological Macromolecules, vol. 117, pp. 385-391, 2018.

[25] X. Peng, G. Yang, Y. Shi, Y. Zhou, M. Zhang, and S. Li, "BoxBehnken design based statistical modeling for the extraction and physicochemical properties of pectin from sunflower heads and the comparison with commercial low-methoxyl pectin," Scientific Reports, vol. 10, no. 1, pp. 1-10, 2020.

[26] U. Kalapathy and A. Proctor, "Effect of acid extraction and alcohol precipitation conditions on the yield and purity of soy hull pectin," Food Chemistry, vol. 73, no. 4, pp. 393-396, 2001.

[27] X. Wang, Q. Chen, and X. Lü, "Pectin extracted from apple pomace and citrus peel by subcritical water," Food Hydrocolloids, vol. 38, pp. 129-137, 2014.

[28] J. A. Lopes da Silva and M. A. Rao, "Galactomannans and other cell wall storage polysaccharides in seeds," in Food Polysaccharides and Their Applications, pp. 181-215, Taylor and Francis Group, 2006.

[29] G. W. Pilgrim, R. H. Walter, and D. G. Oakenfull, "Jams, jellies, and preserves," in The Chemistry and Technology of Pectin, pp. 23-50, Elsevier, 1991.

[30] P. Methacanon, J. Krongsin, and C. Gamonpilas, "Pomelo (Citrus maxima) pectin: effects of extraction parameters and its properties," Food Hydrocolloids, vol. 35, pp. 383-391, 2014.

[31] M. H. Norziah, E. O. Fang, and A. A. Karim, "Extraction and characterisation of pectin from pomelo fruit peels," Gums and Stabilisers for the Food Industry, vol. 10, pp. 27-36, 2000. 
[32] T. Í. S. Oliveira, M. F. Rosa, F. L. Cavalcante et al., “Optimization of pectin extraction from banana peels with citric acid by using response surface methodology," Food Chemistry, vol. 198, pp. 113-118, 2016.

[33] G. E. Barreto, A. L. Púa, D. D. De Alba, and M. M. Pión, "Extracción y caracterización de pectina de mango de azúcar (Mangifera indica L.)," Temas Agrarios, vol. 22, no. 1, pp. 77-84, 2017.

[34] A. do Nascimento Oliveira, D. de Almeida Paula, E. B. de Oliveira, S. H. Saraiva, P. C. Stringheta, and A. M. Ramos, "Optimization of pectin extraction from Ub a mango peel through surface response methodology," International Journal of Biological Macromolecules, vol. 113, pp. 395-402, 2018.

[35] J. Suksaeree, P. Karnsopa, N. Wannaphruek, J. Prasomkij, K. Panrat, and W. Pichayakorn, "Transdermal delivery of nicotine using pectin isolated from durian fruit-hulls-based polymer blends as a matrix layer," Journal of Polymers and the Environment, vol. 26, no. 8, pp. 3216-3225, 2018.

[36] K. Y. Lee and W. S. Choo, "Extraction optimization and physicochemical properties of pectin from watermelon (Citrullus lanatus) rind: comparison of hydrochloric and citric acid Extraction," Science, vol. 5, no. 1, pp. 1-8, 2020.

[37] C. L. O. Petkowicz, L. C. Vriesmann, and P. A. Williams, "Pectins from food waste: extraction, characterization and properties of watermelon rind pectin," Food Hydrocolloids, vol. 65, pp. 57-67, 2017.

[38] J. Prakash Maran, V. Sivakumar, K. Thirugnanasambandham, and R. Sridhar, "Microwave assisted extraction of pectin from waste Citrullus lanatus fruit rinds," Carbohydrate Polymers, vol. 101, no. 1, pp. 786-791, 2014.

[39] A. M. Sari, D. Ishartani, and P. S. Dewanty, "Effects of microwave power and irradiation time on pectin extraction from watermelon rinds (Citrullus lanatus) with acetic acid using microwave assisted extraction method," IOP Conference Series: Earth and Environmental Science, vol. 102, no. 1, p. 012085 , 2018.

[40] J. P. L. Rojas, A. V. Perea, and E. E. Stashenko, “Obtención de aceites esenciales y pectinas a partir de subproductos de jugos cítricos,"Vitae, vol. 16, no. 1, pp. 110-115, 2009.

[41] W. W. Wai, A. F. M. Alkarkhi, and A. M. Easa, "Effect of extraction conditions on yield and degree of esterification of durian rind pectin: an experimental design," Food and Bioproducts Processing, vol. 88, no. 2-3, pp. 209-214, 2010.

[42] H. Mohamed, "Extraction and characterization of pectin from grapefruit peels," MOJ Food Processing \& Technology, vol. 2, no. 1, pp. 31-38, 2016.

[43] H. S. Owens, R. M. McCready, A. D. Shepherd et al., "Methods used at Western Regional Research Laboratory for extraction and analysis of pectic materials," In Bureau of Agricultural and Industrial Chemistry, vol. 340, 2014.

[44] B. Pasandide, F. Khodaiyan, Z. E. Mousavi, and S. S. Hosseini, "Optimization of aqueous pectin extraction from Citrus medica peel," Carbohydrate Polymers, vol. 178, pp. 27-33, 2017.

[45] G. Derringer and R. Suich, "Simultaneous optimization of several response variables," Journal of Quality Technology, vol. 12, no. 4, pp. 214-219, 1980.

[46] USP, "USP Monographs: Pectin," Pharmacopeial Forum, p. 783,2007, http://www.pharmacopeia.cn/v29240/ usp29nf24s0_m61250.html.
[47] JECFA, "Compendium of food additive specifications," in Joint FAO/WHO Expert Committee of Food Additives, FAO JECFA Monofraphs, 2016, http://www.fao.org/3/a-i6413e .pdf\#page $=117 \% 22 \% 3 \mathrm{E}$.

[48] H. Garna, N. Mabon, C. Robert et al., "Effect of extraction conditions on the yield and purity of apple pomace pectin precipitated but not washed by alcohol," Journal of Food Science, vol. 72, no. 1, pp. C001-C009, 2007.

[49] D. L. Su, P. J. Li, S. Y. Quek et al., "Efficient extraction and characterization of pectin from orange peel by a combined surfactant and microwave assisted process," Food Chemistry, vol. 286, pp. 1-7, 2019.

[50] L. Jiang, J. Shang, L. He, and J. Dan, "Comparisons of microwave-assisted and conventional heating extraction of pectin from seed watermelon peel," Advanced Materials Research, vol. 550-553, pp. 1801-1806, 2012.

[51] X. U. E. Z. Zhang, X. Zhang, Z. L. I. U. J. Wang, and Y. C. D. Long, "Optimization of pectin extraction from citrus peel by response surface methodology," Food Science, vol. 32, no. 18, pp. 128-132, 2011.

[52] P. Khamsucharit, K. Laohaphatanalert, P. Gavinlertvatana, K. Sriroth, and K. Sangseethong, "Characterization of pectin extracted from banana peels of different varieties," Food Science and Biotechnology, vol. 27, no. 3, pp. 623-629, 2018.

[53] M. Kuhn, "Desirability: Function Optimization and Ranking via Desirability Functions," 2016, R package version, https:// cran.r-project.org/web/packages/desirability/index.html.

[54] L. D. B. Latorre and J. E. L. Moreno, Pectin extraction from cocoa processing by-products, Process Engineering, 2009.

[55] M. P. Fillippove, "Practical infrared spectroscopy of pectic substances," Topics in Catalysis, vol. 6, no. 1, pp. 115-142, 1992.

[56] A. A. Kamnev, N. M. Ptichkina, M. Ristic, O. G. Shkodina, and V. V. Ignatov, "Comparative spectroscopic characterization of pectins," Spectroscopy of Biological Molecules, vol. 445-446, 1995.

[57] A. Kumar and G. S. Chauhan, "Extraction and characterization of pectin from apple pomace and its evaluation as lipase (steapsin) inhibitor," Carbohydrate Polymers, vol. 82, no. 2, pp. 454-459, 2010.

[58] J. Čopíková, M. Černá, M. Novotná, J. Kaasová, and A. Synytsya, "Application of FT-IR spectroscopy in detection of food hydrocolloids\&nbsp; in confectionery jellies and food supplements," Czech Journal of Food Sciences, vol. 19, no. 2, pp. 51-56, 2013.

[59] J. Perez, K. Gomez, and L. Vega, Optimization and physicochemical characterization of pectin extraction from watermelon rind (Citrullus lanatus) with citric acid, Research Square, 2021. 